This is the final peer-reviewed accepted manuscript of:

Naghavi, A., Peng, S. K., \& Tsai, Y. (2017). Relationship-specific Investments and Intellectual Property Rights Enforcement with Heterogeneous Suppliers. Review of International Economics, 25(3), 626-648.

The final published version is available online at:

https://doi.org/10.1111/roie.12277

Rights / License:

The terms and conditions for the reuse of this version of the manuscript are specified in the publishing policy. For all terms of use and more information see the publisher's website. 


\title{
Relationship-Specific Investments and Intellectual Property Rights Enforcement with Heterogeneous Suppliers*
}

\author{
Alireza Naghavi ${ }^{\dagger} \quad$ Shin-Kun Peng $\ddagger \quad$ Yingyi Tsai ${ }^{\S}$
}

\begin{abstract}
This paper examines the impact of intellectual property rights (IPR) enforcement on multinationals' choice of input suppliers and industry profits in a host economy. The framework consists of suppliers with heterogeneous capabilities who must engage in a relation-specific investment to customize intermediate inputs upon a transfer payment by final producers. An outsourcing contract with better technologically-endowed suppliers requires a lower transfer and generates a higher surplus. Stronger IPR enforcement leads firms to self-select into better quality suppliers on average by reducing their outside option. Weak legal institutions instead make it possible for a larger range of suppliers, including the less capable ones, to form partnerships by granting them a larger outside option. A better IPR environment is more likely to harm lagging countries where the technology distribution is characterized by less capable suppliers.
\end{abstract}

J.E.L. Classification: O34; L24; F21; F23; O32; L22; D23.

Keywords: International outsourcing; Supplier heterogeneity; Relation-specific investment; Intellectual property rights enforcement; Outside option; Customization; Technological capability.

\footnotetext{
${ }^{*}$ We are grateful to two anonymous referees for their valuable feedback and insights which greatly helped us to improve the paper. We are also indebted to James Rauch, Yi-Fan Cheng and Katsunori Yamada for very helpful suggestions. We would like to thank the audience at the APJAE Symposium on Industrial Organization and Global Value Chains (Hong Kong), the Asian Meeting of the Econometric Society (Singapore), the Society for the Advancement of Economic Theory conference (Tokyo) and the seminar participants at Academia Sinica, Taiwan. Financial support provided by Academia Sinica, the National Science Council (NSC-102-2410-H-001-001-MY3), and the Ministry of Science and Technology (MOST 103-2923-H-390-001-MY2) in Taiwan, and by MIUR (PRIN project Institutions, Social Dynamics, and Economic Development) in Italy to enable this international collaboration is gratefully acknowledged.

${ }^{\dagger}$ University of Bologna, Department of Economics. Email : alireza.naghavi@unibo.it.

${ }^{\ddagger}$ Institute of Economics, Academia Sinica, Taipei, Taiwan. E-mail: speng@econ.sinica.edu.tw.

$\S$ Corresponding author: National University of Kaohsiung, Department of Applied Economics, 700 Kaohsiung University Road, Nan-Tze 811, Kaohsiung, Taiwan. Phone: +886-7-5919189, Fax: +886-7-216 9365. Email : yytsai@nuk.edu.tw.
} 


\section{Introduction}

The organization of production and innovation in global supply chains has been subject to recent intense research among trade economists. ${ }^{1}$ The complex contractual relationships between the upstream and downstream firms in international markets have particularly been under the spotlight in studying the organizational decisions of firms, relation-specific investments, and consequences for the economy. A good example used to study supply arrangements has been the Keiretsu models in the Japanese industries, where suppliers undertake relation-specific investments directed at customizing a product to make it more valuable to a particular partner, but not to other potential (rival) buyers. Applications of the Keiretsu models have been brought into the ambit of international trade by Qiu and Spencer $(2001,2002)$. This type of relationship between assemblers and suppliers is especially prevalent in the Japanese automotive sector (Ahmadijan and Oxley, 2006, 2013).

This paper constitutes one of the first attempts to introduce supplier heterogeneity into a model of global sourcing, a step deemed necessary both from a theoretical and an empirical perspective in the literature of firm organization (Antràs, 2014). Indeed, the business and economic literature has to a great extent treated first-tier suppliers as being similar in nature. A closer look within industries, however, reveals a different reality, and more so after the 21st century trends towards the globalization of outsourcing strategies. Suppliers' heterogeneity issues have been discussed in Kamath and Liker (1994), who observe that suppliers have different effects on the manufacturers and that their roles with regards to innovation vary extensively. Their study on the Japanese and the American automotive industry reveals for example that few suppliers can make the full investment in personnel, computer-aided-design (CAD) systems, prototyping facilities, and R\&D capabilities that a true partnership with their final producer requires. Suppliers tend to be reluctant to station engineers full-time in their partners' offices or to devote substantial resources to the development of goods and technologies customized to a final producer that will be of no use to them after a few years. ${ }^{2}$ Also Sutton (2004) shows the vast heterogeneity across the capability of auto part suppliers in India and China to achieve the quality required on the components supplied to multinational car makers. The investigation examines the range of quality by measuring the number of defects found in incoming components. ${ }^{3}$ Finally, UNCTAD (2001) provides evidence that multinationals reduce their operations to only deal with selected range of the best suppliers, which are able to comply with international standards. Superior knowledge and technology make some suppliers more attractive and of higher competitive significance to manufacturers in the global market. Linkages

\footnotetext{
${ }^{1}$ See Helpman (2006) for a thorough overview.

${ }^{2}$ See Kamath and Liker (1994) for a more detailed explanation of the survey on auto-part suppliers to Toyota, Nissan, Mazda, General Motors, Ford, and Chrysler.

${ }^{3}$ In particular, half of suppliers achieved a figure under 100 parts per million (ppm) defective, 17\% from 100 to 300 ppm, around 10\% under 700 ppm, 6\% in China and 20\% in India under 1500ppm, and one-eighth of suppliers had defect rates exceeding 1500 .
} 
with multinational enterprises can also have consequences for the domestic economy as a whole by affecting competition and the quality of the supply chain, which in turn depends on firms' choice of suppliers.

Yet, how do multinationals decide their global sourcing strategy and select suppliers for the procurement of their relation-specific inputs? Do they always rely on the best few first-tier suppliers in each country or do they behave differently in different environments when choosing their subcontractor? This research aims to provide a theory in order to explain the patterns of outsourcing relationships between multinational firms and suppliers. Suppliers are heterogeneous in terms of their technological capability in host countries that are characterized by their legal institutions. Introducing supplier heterogeneity in the upstream market in the spirit of Andrabi, Ghatak and Khwaja (2006), we can investigate the decisions of firms in the formation of outsourcing contracts with assorted suppliers. We emphasize differences (or improvements) in institutional quality to explore how intellectual property rights (IPR) enforcement may influence the supplier mix and examine the effect of supplier choice on the domestic economy.

More specifically, final producers source to a continuum of suppliers that are heterogeneous with respect to their ability in undertaking relation-specific investments. Suppliers must commit to make an investment that can be interpreted as a customization (or R\&D) cost, the extent of which depends on their ability to carry out the relation-specific task. Less technologically-endowed suppliers are required to make a larger investment to satisfy the multinational's needs. After finding a partner, final producers are bound to make a payment to their supplier to cover a part of the necessary investment, in order to minimize hold-up problems in the upstream-downstream relationship. The more technologically capable the suppliers are, the lower that the required payment is. Consequently, a higher joint surplus is generated within the relationship.

The framework adds a further important feature often overlooked in the literature when assessing multinationals' links with the most capable suppliers: the outside option of suppliers in outsourcing relationships. ${ }^{4}$ Multinationals on average tend to outsource to suppliers with better R\&D capabilities in countries with stronger IPR institutions. IPR enforcement ensures adequate relation-specific investment by lowering the supplier's outside option and hence the probability of defection. By contrast, when the IPR environment is weak, supplier technology plays a less important role and buyer-supplier relations are also formed with less capable suppliers. This is because weak legal institutions provide them with an outside option that increases their chances of survival in the market.

Introducing heterogeneity among suppliers also allows us to make predictions regarding the consequences of IPR enforcement for the host economies. The results suggest that the impact of increasing

\footnotetext{
${ }^{4}$ The few previous works that have touched upon the issue include Andrabi, Ghatak and Khwaja (2006), Lin and Saggi (2007) and Assche and Schwartz (2010).
} 
$R \& D$ efficiency in the intermediate sector by creating a more stringent IPR environment in the home economy is ambiguous. An enhancement in the average technology of rivals in the economy lowers average profits and makes it harder for less capable suppliers to survive in the market. On the one hand, less competition increases the profitability of the most technologically capable suppliers in the intensive margin. On the other hand, a reduced number of active suppliers lowers the number of firms and hence aggregate profits on the extensive margin. The effect of IPR enforcement is more likely to be negative for technologically lagging host countries with a fat right tail distribution of suppliers with inferior technologies. A shrinking upstream sector serving foreign producers caused by better quality IPR institutions can in this case be harmful to the economy. This is in line with Che, Qiu, and Zhou (2014) who show that holding constant a multinational's incentive to innovate, better IPR enforcement encourages entry but reduces social welfare.

The rest of the paper is organized as follows. Section 2 discusses the related literature and evidence. Sections 3 introduces the basics of the model. Section 4 solves the equilibrium and presents the results. Section 5 concludes.

\section{Related Literature and Evidence}

The organization of firms was first incorporated into trade theory by McLaren (2000) and Grossman and Helpman (2002). These papers also studied the degree to which suppliers decide to customize intermediate products to the needs of their intended buyer. This is the emphasis of Grossman and Helpman (2003), who use the transaction cost approach to find that better contract enforcement increases the fraction of firms that engage in outsourcing. ${ }^{5}$ Grossman and Helpman (2005), however, show that in a general equilibrium setting an improvement in the contractual environment in the South can raise or lower the volume of outsourcing there. Antràs and Helpman (2008) turn the page to the property-right theory to show that improvements in the contractibility of components provided by suppliers in the South increases the relative prevalence of FDI over outsourcing.

As for the effect of contract enforcement on the economy, another branch of the literature uses a measure of contract dependence to show that countries with well-functioning contractual institutions will be net exporters of contract-intensive goods. Acemoglu, Antràs, and Helpman (2007) show that greater contractual incompleteness leads to the adoption of less-advanced technologies with a more pronounced effect when there is greater complementarity among intermediate inputs. Costinot (2009) derives the result that countries with better contracting institutions have a comparative advantage in more complex sectors. Levchenko (2007) and Nunn (2007) suggest measures of contract dependence related to the costs of contracting between upstream and downstream producers and provide empirical evidence that a country's comparative advantage is partly determined by

\footnotetext{
${ }^{5}$ See Defever and Toubal (2013) among others for evidence that supports this hypothesis.
} 
contracting institutions.

Despite the vast literature on outsourcing and incomplete contracts, the role of IPR enforcement in the outsourcing decision of multinationals remains to a large extent unexplored in economic literature. On this regard, Antràs and Rossi-Hansberg (2009) emphasize the effects of the non-appropriable nature of knowledge on the organizational decision of firms, suggesting that past literature has concentrated too much on hold-up inefficiencies as the main drivers of outsourcing decisions. As for evidence on multinational activities, Branstetter, Fisman, and Foley (2006) show that technology transfer by US multinationals to their affiliates increase after IPR reforms. Ivus (2010) finds that increasing IPRs in developing countries raises the value of developed countries' exports in patent-sensitive industries. Canals and Şener (2014) show that US firms substantially expand their intra-industry offshoring activities in high technology industries as a response to IPR reforms in the host countries. Naghavi, Spies, and Toubal (2015) further show that technologysharing outsourcing of more sophisticated goods by French multinationals take place in countries with better IPR enforcement. Despite clear evidence on technology transfer, however, controversies on the appropriateness of IPR protection in the developing and emerging world persist. Lai and Qiu (2003) debate the suitability of North's IPR standards for the South, whereas Chu, Cozzi, and Galli (2014) argue the relevance of the stage of development for the protection of IPRs.

In this paper, we focus on the impact of the quality of IPR institutions on industry profits in the supply chain in the destination country. In particular, we follow Grossman and Helpman (2005) to explore the location decision of firms that have already decided to engage in international outsourcing and its impact on the supplier market and subsequently the host economy. While local manufacturers may not need hefty investments from their local input suppliers, the number of suppliers that can meet the customization standards required by multinational firms are more limited. ${ }^{6}$ As a result, only the most qualified suppliers enjoy technology transfer through the outsourcing partnership because multinationals tend to focus their supplier development efforts on their key (most technologically capable) suppliers. Parallel to Melitz (2003), we therefore start from the underlying assumption that globalization has weakened the position of less efficient suppliers in host developing economies and made it more difficult for them to survive. Our paper adds to this argument by showing that the quality of IPR enforcing institutions in a host country decides the magnitude of this effect.

\footnotetext{
${ }^{6}$ Although we only study the case of international outsourcing, it is important to keep in mind that foreign firms tend to be in a different position than local firms: they come from a world market where firms enjoy established suppliers aware of their technical/quality needs. As a result, it would only be worthwhile for multinationals to go to the best available suppliers.
} 


\section{The Model with Heterogeneous Suppliers}

The economy consists of two countries, North and South. We focus on an industry that produces an endogenous number of differentiated consumer goods. The goods are designed and assembled in the North, whereas the production of the required intermediate goods is outsourced to the South. The goods specifically target consumers in the North. The South therefore plays the role of a production site. We can think of a reduced form explanation, where final producers are multinationals and outsource the production of their intermediates to a host country. We are interested in studying the interaction between multinational firms and input suppliers, and the impact of outsourcing to heterogeneous suppliers on the host economy given that the outsourcing decision has already taken place for motives such as lower wages or the higher efficiency of intermediate specialists.

The only factor needed for the production of the intermediate good is labor. Production of the final good in turn uses these inputs, in such a way that one unit of the intermediate good is required to produce one unit of the final good. Moreover, because of the differentiated nature of final goods, suppliers must customize their intermediate good perfectly so that it can only be used by that particular producer. Customization costs in our model take into account the explicit form of learning costs that an input supplier has to incur to acquire the necessary technology, management and marketing techniques to compete in the world market. The final producer can provide support for part of the training and technology transfer costs through a payment to partially reimburse the investment.

Suppliers are heterogeneous in terms of fixed customization/R\&D costs, but all face the same marginal costs once they start producing. The proposed formulation implies that some suppliers adapt easier than others to final producers' requirements and hence need less external support to achieve the targeted customization. The more technologically-endowed that the supplier is prior to the partnership, the lower that the required payment to guarantee the desired quality of standards is. More capable suppliers therefore yield a higher surplus, which makes them a more attractive target.

\subsection{Consumers}

The consumption of the final good takes place in the North. Households share the same preferences with their utility defined over the consumption of a horizontally differentiated good $C$, where

$$
C=\left[\int_{0}^{n} c_{j}^{\alpha} d j\right]^{\frac{1}{\alpha}}
$$

is a CES quantity index in which $c_{j}$ is the consumption of variety $j, n$ is the number of varieties

produced, and $0<\alpha<1$ is an inverse measure of the degree of product differentiation between varieties. Households maximize consumption subject to the following constraint 


$$
E=w L_{N}=\int_{0}^{n} p_{j} c_{j} d j
$$

where $p_{j}$ is the price of variety $j$, and the expenditure consumers incur on output from the industry, $E$, equals aggregate income, $w L_{N}$, with $L_{N}$ representing total labor used in the industry under the common assumption of an infinite supply of labor at an exogenously set market wage rate, $w>1$.

The utility maximizing profit results in the demand for the $j^{t h}$ variety of the form

$$
c_{j}=A p_{j}^{-\sigma}
$$

where $A$ is the aggregate demand associated with the quantity index $C$ and is defined as

$$
A=\frac{E}{\int_{0}^{n} p_{j}^{1-\sigma} d j}
$$

and $\sigma=\frac{1}{1-\alpha}$ is the elasticity of substitution.

\subsection{Firms}

Upon payment of an initial fixed search cost $f_{e}$ by a pair of potential partners to enter the market, the technology level of the intermediate supplier $\zeta$ is revealed from a distribution $g(\zeta)$ with a continuous cumulative distribution $G(\zeta) \in[0,1]$ where $G(1)=0, G(\infty)=1$. With $\zeta^{*}$ as a threshold capability above which suppliers find it profitable to enter, $1-G\left(\zeta^{*}\right)$ represents the range of existing suppliers in the market. The parameter $\zeta$ can also be interpreted as the firm's marginal capacity of technology absorption. It determines a cost in terms of the level of labor effort they have to make in order to adapt to the technological needs of the representative final producer. Once (potential) suppliers learn their customization capabilities, they go to the market where they negotiate contracts with final firms. They must pay a fixed cost $k_{s}$ in terms of Southern labor to start producing, where the market wage in the host country is normalized to one. Whenever a partnership is successful, production starts. Once in business, all suppliers need one unit of labor to produce one unit of the intermediate good, irrespective of $\zeta$.

Final firms in turn engage in production upon payment of a fixed cost $w k_{f}$ in terms of Northern labor. They then look for a supplier and upon success propose their desired prototype, and begin the two-step negotiation. In general, they will have to incur costs that relate to a customization payment or know-how transfer. We will see that this required payment will decrease in $\zeta$. Final firms that have managed to form a successful partnership compete in a typical Dixit-Stiglitz manner: each pair of firms is a monopolist in the production of a differentiated good. They pay a fixed cost each period and use the intermediate good to produce and market their variety. Thus we assume that final producers have no variable costs and can therefore consider them to be homogeneous in 
terms of productivity. It will be seen in Section 4.3 how things differ if heterogeneity is instead in the variable cost of suppliers, i.e. their productivity.

\subsection{Contracts}

Any active firm in this economy is part of a partnership composed of a supplier of customized intermediate inputs and a final producer in charge of the assembly, marketing and distribution of (differentiated) final goods. Prior to commencing production, firms meet in pairs and negotiate the terms of their future relations. Any supplier is a priori capable of customizing inputs to any formulation required. Moreover, even though final producers manufacture differentiated goods, the cost of building the right prototype is the same for all goods.

The negotiation takes place after the two parties meet under the assumption that pairs are always formed (no search frictions). Following Grossman and Helpman (2005), such a negotiation can be thought of as being composed of two stages. Assume that the final producer owns all the know-how about its particular product. In the first stage, it transmits the information about the exact type of intermediate input it requires to the (prospective) supplier. We may call this stage the investment contract, where we make explicit that the supplier needs to incur an investment cost in order to close a deal. This contract commits the supplier to undertake the investment in customization so that an acceptable prototype is created. The contract stipulates a payment to which the supplier is entitled if the prototype is satisfactorily developed.

Once the supplier has undertaken the necessary investment to manufacture the required prototype, the two parties move on to the second stage of negotiations. The two firms write an order contract through which they stipulate the quantities that the final producer will demand and the associated price. Incentives are fully aligned at this stage as both firms have sunk investments, and the only plausible source of income available to them is the joint surplus that arises from their relationship. Thus, the order contract will be the joint profit maximizing one, the quantity stipulated will be the quantity of inputs needed to satisfy the demand for final goods in the market, and the price of the intermediate good will be at its minimum level, i.e., the supplier's marginal cost. ${ }^{7}$

\subsubsection{The Order Contract}

The order contract determines the surplus arising from a successful partnership. As discussed before, the optimum strategy at this stage is to maximize joint variable profits (revenue), since all fixed costs are already sunk. Recall that firms are monopolists in the production of their own $j^{\text {th }}$ variety, and so they pick the optimum price facing a downward-sloping demand curve derived from the consumer's

\footnotetext{
${ }^{7}$ It will never be optimal for the supplier to charge a higher price, since that would result in a higher marginal cost for the final producer, and a higher-than-optimal price which entails lower joint profits.
} 
maximization problem. We further denote the profit share that accrues to the final producer and the supplier by $[1-\omega]$ and $\omega$, respectively.

The $j^{\text {th }}$ partnership maximizes

$$
R_{j}=\pi_{f}+\pi_{s}=p_{j} y_{j}-x_{j}
$$

where $y_{j}=c_{j}$ is the demand and $x_{j}$ is the quantity of the intermediate good. This is divided according to the bargaining power of each side so that a share $[1-\omega]$ goes to the final producer and $\omega$ to the intermediate supplier.

By the assumption that one unit of intermediate goods is required to produce one unit of final goods and with iceberg costs on intermediate goods $\tau>1$, we have $y_{j}=\frac{x_{j}}{\tau}$. Thus, we may rewrite

$$
R_{j}=p_{j} \frac{x_{j}}{\tau}-x_{j}=\left(\frac{p_{j}}{\tau}-1\right) x_{j}=\tau A p_{j}^{-\sigma}\left(\frac{p_{j}}{\tau}-1\right)
$$

The first-order condition yields $p_{j}=\tau \frac{\sigma}{\sigma-1}$, and hence a price

$$
p_{j}=\tau \frac{\sigma}{\sigma-1}=\frac{\tau}{\alpha}
$$

where $\frac{1}{\alpha}=\frac{\sigma}{\sigma-1}$ is the mark-up over marginal cost resulting from the monopoly position of a firm in the production of its specific variety. As usual, this mark-up is inversely related to the elasticity of substitution: $\frac{\partial(1 / \alpha)}{\partial \sigma}<0$, that is, it is positively related to the degree of product differentiation. The more that the pair of goods are substitutes, the less the market power that each firm has and thus the lower the price that it charges.

The quantity effectively demanded of each good $j$ equals $c_{j}=A p_{j}^{-\sigma}=A\left(\frac{\tau}{\alpha}\right)^{-\sigma}$, which is equal to the demand for the intermediate good. Total revenue is therefore

$$
R_{j}=(1-\alpha) A\left(\frac{\tau}{\alpha}\right)^{1-\sigma}
$$

Using (7), we redefine aggregate demand as

$$
A=\frac{E}{n\left(\frac{\tau}{\alpha}\right)^{1-\sigma}},
$$

where the number of varieties $n$ also represents the number of paired suppliers and final producers. Replacing (9) in (8), we can rewrite the operating profit of each type of firm in its final form

$$
\pi_{f}=[1-\omega](1-\alpha) \frac{E}{n}
$$

and

$$
\pi_{s}=\omega(1-\alpha) \frac{E}{n}
$$

Note that the trade costs disappear as a higher price is offset by a lower demand for the final good. 


\subsubsection{The Investment Contract}

Each supplier faces a constant customization investment $\iota$ for the relation-specific asset. The total cost for a supplier with capability $\zeta$ is equal to $I=\iota / \zeta$ so that those with a better technology draw need to devote less effort in terms of labor to create the required prototype. The supplier also has the outside option of using the know-how provided by final producers for its own benefit by serving the local market. The idea is that after investing in the R\&D cost, the supplier can sell the technology to other firms in the perfectly competitive local market at a price equal to the $\mathrm{R} \& \mathrm{D}$ investment, subject to IPR enforcement. In other words, they can recover the R\&D investment cost, $I$, by selling to the local market with IPR protection creating a cost of defecting, thereby partially deterring this possibility. Our specification thus implicitly incorporates an outside option for suppliers equivalent to $O=(1-\gamma) I$, where $\gamma \in(0,1]$ represents the cost of defecting.

The final firm needs to give incentives to the supplier and does so by promising an up-front payment $T$ towards the completion of the investment. The profits of the supplier can be written as

$$
\Pi_{s}=\pi_{s}-I+O+T=\pi_{s}-\gamma \iota / \zeta+T .
$$

IPR enforcement therefore obliges a supplier to invest more within the relationship, i.e. a proportion $\gamma$ of the required relation-specific investment. The final firm's operating profits are in turn

$$
\Pi_{f}=\pi_{f}-T .
$$

The payment $T \equiv T(\zeta, \gamma)$ comes out of a Nash generalized bargaining process, through which both parts maximize joint profits by anticipating their share of those profits:

$$
T(\zeta, \gamma)=[1-\omega] \gamma \iota / \zeta
$$

Lemma 1 The transfer payment required by a subcontractor that satisfies the Nash bargaining outcome $T(\zeta, \gamma)$ is lower for more capable suppliers because they need less support as their investment costs to customize are lower.

Proof. This follows directly from the Nash bargaining solution (14).

After replacing $T(\zeta, \gamma)$ in (12) and (13) from (14) we can rewrite the profits functions of each type of firm

$$
\begin{gathered}
\Pi_{s}=\frac{(1-\alpha) \omega E}{n}-\gamma \iota / \zeta+[1-\omega] \gamma \iota / \zeta=\omega\left(\frac{E}{n}(1-\alpha)-\gamma \iota / \zeta\right) \\
\Pi_{f}=\frac{(1-\alpha)[1-\omega] E}{n}-[1-\omega] \gamma \iota / \zeta=[1-\omega]\left(\frac{E}{n}(1-\alpha)-\gamma \iota / \zeta\right)
\end{gathered}
$$


for the supplier and the final firm, respectively.

\section{Equilibrium}

\subsection{Supplier Zero Cut-Off Conditions}

Suppliers enter into outsourcing relations after paying the production fixed cost, $k_{s}$, with the expected gains of a supplier with technology $\zeta$ from a partnership being $\Pi_{s}-k_{s}$.

Using (15), the zero cut-off condition for the supplier implies that

$$
k_{s}=\Pi_{s}=\pi_{s}-\gamma \iota / \zeta+T(\zeta, \gamma)=\omega\left(\frac{E}{n}(1-\alpha)-\gamma \iota / \zeta^{*}\right)
$$

The cut-off $\zeta$ needed, below which a supplier is required to make an investment it cannot afford and hence cannot serve the multinational, is

$$
\zeta^{*}=\frac{\gamma \iota}{\frac{E}{n}(1-\alpha)-\frac{k_{s}}{\omega}} .
$$

Note that the cut-off $\zeta^{*}$ above which suppliers find it profitable to enter into a relationship is decreasing in $\omega$, which implies that a larger share $\omega$ tends to create a more favorable condition for less technologically capable suppliers to also enter relationship-specific contracts.

The final good producer who enters a partnership with the threshold supplier earns

$$
w k_{f}=\Pi_{f}=\pi_{f}-T(\zeta, \gamma)=[1-\omega]\left(\frac{E}{n}(1-\alpha)-\gamma \iota / \zeta^{*}\right)
$$

where profits are equal to $w k_{f}$ to satisfy the zero profit condition. By substituting the capability of the threshold supplier from (18) into (19) we obtain

$$
\frac{w k_{f}}{k_{s}}=\frac{1-\omega^{*}}{\omega^{*}} \Longrightarrow \omega^{*}=\frac{k_{s}}{w k_{f}+k_{s}} .
$$

Lemma 2 The profit share going to the threshold supplier $\omega^{*}$ can be interpreted as the industry's (i) inverse measure of market thickness in the upstream intermediate inputs market, and (ii) level of upstream representation or the importance of the role of suppliers in partnerships, being determined by the suppliers' relative fixed costs to produce within the relationship.

Proof. This follows directly from the condition (20).

The value $\omega^{*}$ can be thought of as an initial condition that determines the industry characteristics. It is the minimum share required by suppliers in an industry. More precisely, it is the share paid to the threshold supplier that makes both sides break even. The derivative $\frac{\partial \omega^{*}}{\partial k_{s}}>0$ shows that lower fixed costs encourage more suppliers to enter outsourcing relationships, thereby increasing the thickness in the input market. ${ }^{8}$ It can be also interpreted as an industry in which suppliers

\footnotetext{
${ }^{8}$ In McLaren (2000), the thicker the market for inputs, the larger is the ex-post share of the surplus obtained by suppliers, which in turn alleviates the hold-up inefficiencies. In Grossman and Helpman (2002) instead, a thicker market for inputs enhances the probability of finding a match, which increases the attractiveness of outsourcing.
} 
have a relatively higher representation or importance in outsourcing relationships (a higher relative production fixed cost) and therefore require a larger share. It will be seen that the positive surplus in outsourcing relations with suppliers above the threshold will be divided according to the bargaining power of each side, which does not play an important role in our results.

We now rewrite $\zeta^{*}$ for the threshold supplier by substituting $\omega^{*}$ obtained in (20) back into (18) to get a cut-off technology level that just compensates for the fixed production costs of both partners:

$$
\zeta^{*}(\gamma)=\frac{\gamma \iota}{\frac{E}{n}(1-\alpha)-w k_{f}-k_{s}} .
$$

\subsection{Final Good Market Entry}

Equation (16) infers that there exists a threshold level of supplier capability under which they no longer find it worthwhile to enter a partnership. For any given level of supplier capability, the $\zeta$ that makes the final producer break even is

$$
\zeta=\frac{\gamma \iota}{\frac{E}{n}(1-\alpha)-\frac{w k_{f}}{\left(1-\hat{\omega}_{f}\right)}},
$$

where $\hat{\omega}_{f}$ is the share of the surplus paid to the supplier that satisfies the final firms' zero profits condition:

$$
\hat{\omega}_{f}=1-\frac{w k_{f}}{\frac{E}{n}(1-\alpha)-\gamma \iota / \zeta} .
$$

The supplier share that gives the final producer zero profits is increasing with a supplier's R\&D capability as this requires a lower transfer. This suggests that the better a supplier is (the less investment cost it bears), the higher is the share of the surplus that a final producer can afford to give up and still break even.

\subsection{Formation of Outsourcing Relations}

As in Melitz (2003), we focus on steady state equilibria. A pair of firms, the supplier in which has the technology level $\zeta$, earn a joint surplus $\Pi(\zeta)$ in each period, until hit by a shock, at which point they exit the market. A pair seeking to start operations expect a discounted value of profits equivalent to:

$$
v(\zeta)=\max \left\{0, \sum_{t=0}^{\infty}(1-\delta)^{t} \Pi(\zeta)\right\}=\max \left\{0, \frac{1}{\delta} \Pi(\zeta)\right\},
$$

where an anticipated negative operating profit makes the two sides exit the potential contract upon observing $\zeta$. We now know there is a unique threshold $\zeta^{*}$ such that $v(\zeta)>0$ if $\zeta>\zeta^{*}$.

In the industry equilibrium, we have to solve for the number of paired partners (and varieties) $n$ and the cut-off $\zeta^{*}$. To do this we must first determine the average joint surplus $\bar{\Pi}$. This can be easily calculated by using the share $\hat{\omega}_{f}$ from (23) to set the profits of the final producers equal to 
zero and solve for supplier average profits $\bar{\Pi}_{s}=\Pi_{s}(\tilde{\zeta})-k_{s}$. It is also possible to do the opposite, giving the final producer full bargaining power. By doing so, we obtain the share $\hat{\omega}_{s}=\frac{w k_{s}}{\frac{E}{n}(1-\alpha)-\gamma \iota / \zeta}$ that sets supplier profits equal to zero and solve for $\bar{\Pi}_{f}=\Pi_{f}(\tilde{\zeta})-w k_{f}$. The derivations yield the exact same results as the two sides simply maximize joint profits at the order contract stage.

We start by using the ratio technique in the spirit of Melitz (2003), which gives

$$
\frac{\gamma \iota / \zeta_{1}}{\gamma \iota / \zeta_{2}}=\frac{\zeta_{2}}{\zeta_{1}} \Longrightarrow \gamma \iota / \tilde{\zeta}=\left(\frac{\zeta^{*}}{\tilde{\zeta}\left(\zeta^{*}\right)}\right) \gamma \iota / \zeta^{*}
$$

where we define $\tilde{\zeta}\left(\zeta^{*}\right)$ as the average technology of suppliers that are active in the market. This allows us to calculate the average customization investment for suppliers using the cut-off level in (21):

$$
\gamma \iota / \tilde{\zeta}=\left(\frac{\zeta^{*}}{\tilde{\zeta}\left(\zeta^{*}\right)}\right) \gamma \iota / \zeta^{*}=\left(\frac{\zeta^{*}}{\tilde{\zeta}\left(\zeta^{*}\right)}\right)\left[\frac{E}{n}(1-\alpha)-w k_{f}-k_{s}\right]
$$

The average payment, on the other hand, can be found by substituting (24) in (14) and is

$$
\tilde{T}=\left[1-\hat{\omega}_{f}\right] \gamma \iota / \tilde{\zeta}=\left[1-\hat{\omega}_{f}\right]\left(\frac{\zeta^{*}}{\tilde{\zeta}\left(\zeta^{*}\right)}\right)\left[\frac{E}{n}(1-\alpha)-w k_{f}-k_{s}\right]
$$

Relegating the calculations to the Appendix, we can derive the first equation of our system, which simplifies to

$$
\bar{\Pi}=\pi_{s}+\tilde{T}-\gamma \iota \tilde{\zeta}-k_{s}=\left[\frac{E}{n}(1-\alpha)-w k_{f}-k_{s}\right] \kappa\left(\zeta^{*}\right)
$$

where

$$
\kappa\left(\zeta^{*}\right)=1-\frac{\zeta^{*}}{\tilde{\zeta}\left(\zeta^{*}\right)}
$$

In line with Melitz (2003), we observe from (26) that since a higher $\zeta^{*}$ increases average capability, it directly increases the average joint surplus. There is, however, also a negative effect because the capabilities of rival firms are also increasing. The latter effect tends to dominate if $G(\zeta)$ has a sufficiently fat right tail so that $\kappa\left(\zeta^{*}\right)^{\prime}<0$, making the ZCP schedule (26) downward sloping in $\zeta^{*}$.

The ex-ante probability of successful entry is

$$
\rho_{e}\left(\zeta^{*}\right) \equiv 1-G\left(\zeta^{*}\right)
$$

Recall that both sides of the relationship make investments $w k_{f}$ and $k_{s}$ to enter a partnership when they have an expectation of future positive profits. Let $\bar{v}$ represent the present value of the average flow of the joint surplus:

$$
\bar{v}=\frac{1}{\delta} \bar{\Pi}
$$

The net value of entry can be defined as

$$
v_{e}=\rho_{e} \bar{v}-f_{e}=\frac{1-G\left(\zeta^{*}\right)}{\delta} \bar{\Pi}-f_{e} .
$$

Thus, the free entry condition yields the second equation of our system

$$
\bar{\Pi}=\frac{\delta f_{e}}{1-G\left(\zeta^{*}\right)}=\frac{\delta f_{e}}{\rho_{e}\left(\zeta^{*}\right)},
$$


which is increasing in $\zeta^{*}$.

The novelty of the model is that it deals with $R \& D$ costs which are generally encompassed in the fixed part of the cost function of firms. This gives heterogeneity in technological capability and IPR protection a role in the upstream-downstream relationship between firms, and in determining the market structure. In our setting, moving heterogeneity from the fixed to the variable component of the cost function would reduce the model to a standard Melitz (2003) heterogeneous firm framework where investment takes the shape of fixed cost $\frac{\gamma \iota}{\zeta}$ with a constant $\zeta$. Heterogeneity would instead be relevant for the order contract now (as opposed to the investment contract that involves technology) with supplier productivity determining the outsourcing decision of firms. Equation (7) turns to

$p_{j}(\varphi)=\frac{\tau}{\alpha \varphi_{j}}$ with $\varphi_{j}$ representing supplier productivity, and investment $\frac{\gamma \iota}{\zeta}$ simply becomes another fixed cost added to the previous ones and can therefore be embedded in $k_{s}$. More precisely, solving the model yields average joint profits $\bar{\Pi}=\frac{E}{n}(1-\alpha)-w k_{f}-k_{s}-\frac{\gamma \iota}{\zeta}=\left[w k_{f}+k_{s}+\frac{\gamma \iota}{\zeta}\right] \kappa\left(\varphi^{*}\right)$ in place of Equation (27), where $\kappa\left(\varphi^{*}\right)=\left(\frac{\tilde{\varphi}\left(\varphi^{*}\right)}{\varphi^{*}}\right)^{\sigma-1}-1$. This corresponds to the zero cutoff point (ZCP) schedule in Melitz (2003), where $\bar{\Pi}=f \kappa\left(\varphi^{*}\right)$. Here it is true that the cut-off supplier productivity is increasing in IPR protection level $\gamma$, but this is of little insight as a larger $\gamma$ simply implies a higher fixed cost, and a higher productivity level is required to cover it and start production.

\subsection{Industry Equilibrium and IPR Enforcement}

The two equations (26) and (29) together with two unknowns $n$ and $\zeta^{*}$ can now be explicitly solved to close the model. By equating the two equations obtained for $\bar{\Pi}$, we solve for the number of relations (paired upstream and downstream firms), $n$, which is also equivalent to the number of varieties:

$$
n=\frac{E(1-\alpha)}{\frac{\delta f_{e}}{\rho_{e}\left(\zeta^{*}\right) \kappa\left(\zeta^{*}\right)}+w k_{f}+k_{s}},
$$

where we have used definitions (27) and (28). It is easy to see that $\frac{\partial n}{\partial \zeta^{*}}<0$. Replacing $n$ from (30) in (21) gives the zero cut-off technology level in its final form and thereby the equilibrium condition:

$$
\frac{\zeta^{*}}{\kappa\left(\zeta^{*}\right) \rho_{e}\left(\zeta^{*}\right)}=\frac{\gamma \iota}{\delta f_{e}}
$$

An increase in the RHS of (31) caused by a larger $\gamma$ or a lower entry cost must be accompanied by an increase in the LHS made possible by a higher $\zeta^{*}$ (given that $\kappa^{\prime}\left(\zeta^{*}\right)<0$ and $\rho_{e}^{\prime}\left(\zeta^{*}\right)<0$ ) to satisfy the equilibrium condition. We can therefore state the following proposition:

Proposition 1 The cut-off technology level of suppliers is increasing with stronger IPR enforcement, $\frac{\partial \zeta^{*}(\gamma)}{\partial \gamma}>0$, making it more difficult for less technologically capable firms, which are deprived of their outside option, to lie within the range of technological capabilities governed by a contract. A more stringent IPR environment therefore induces final producers to choose suppliers that are on average more technologically capable as outsourcing partners, i.e., $\tilde{\zeta}^{\prime}\left(\zeta^{*}\right)>0$. 
Proof. This follows directly from the equilibrium condition in (31) derived from (30) and (21). Using the definition of the weighted average supplier technological capability from the Appendix, differentiating average supplier capability with respect to $\zeta^{*}$ yields:

$$
\tilde{\zeta}^{\prime}\left(\zeta^{*}\right)=\frac{g\left(\zeta^{*}\right)\left(\tilde{\zeta}\left(\zeta^{*}\right)-\zeta^{*}\right)}{1-G\left(\zeta^{*}\right)}>0,
$$

which is always positive because $\tilde{\zeta}\left(\zeta^{*}\right)>\zeta^{*}$.

Proposition 1 has important implications. The conventional wisdom suggests that final producers tend to choose suppliers with better technologies to pair with. The results show that this is to a greater extent the case in countries with better IPR institutions: the average technology of suppliers is higher in countries with stronger IPR enforcement. A better legal environment reduces the outside option of less capable suppliers, making only suppliers with better technologies survive since firms are obliged to invest more within the contractual relationship. In contrast, under weak IPR institutions, less capable suppliers are provided with a larger outside option enabling them to also enter into outsourcing relationships.

Our final aim is to study the impact of IPR enforcement and in turn the outsourcing decisions by multinationals on the host economy. To do this recall that consumption of the final good takes place in the North. Given that a positive share of the surplus $\omega>0$ goes to the suppliers and is superior to the pay-off outside the relationship after exiting the market, the total profits earned from economic activities that take place in the industry can be used to measure the industry gains in the Southern economy that arise from outsourcing relationships. ${ }^{9}$ To do so, we multiply Equations (29) and (30) to obtain

$$
n \bar{\Pi}=\frac{\delta f_{e} E(1-\alpha)}{\left[1-G\left(\zeta^{*}\right)\right]\left(\frac{\delta f_{e}}{\rho_{e}\left(\zeta^{*}\right) \kappa\left(\zeta^{*}\right)}+w k_{f}+k_{s}\right)}=\frac{E(1-\alpha)}{\frac{1}{\kappa\left(\zeta^{*}\right)}+\frac{\rho_{e}\left(\zeta^{*}\right)\left(w k_{f}+k_{s}\right)}{\delta f_{e}}},
$$

where we have used the definition for $\rho_{e}\left(\zeta^{*}\right)$ from (28). ${ }^{10}$ Equation (32) immediately reveals that the impact of an upward shift in $\zeta^{*}$ that occurs due to strengthening IPR enforcement is ambiguous and depends on the technology distribution. Since $\kappa^{\prime}\left(\zeta^{*}\right)<0$ and $\rho_{e}^{\prime}\left(\zeta^{*}\right)<0$, we observe two effects. The positive effect is due to an increase in the profits of the remaining more technologically capable suppliers in the intensive margin brought about by reduced competition, a lower $\rho_{e}\left(\zeta^{*}\right)$. This occurs as a consequence of protection against the entry of more firms into the market. The negative effect appears due to lower supplier profits on the extensive margin that come from a reduced number of active firms in the industry due to stronger rivals in the market, a lower $\kappa\left(\zeta^{*}\right)$.

\footnotetext{
${ }^{9}$ While condition $L_{N}=w k_{f}$ can be used to determine consumption in the North, labor in the South used to produce the intermediate goods in the industry under study is equal to $L_{S}=n\left(\tilde{x}+\gamma \iota / \tilde{\zeta}+k_{s}\right)$. This is however irrelevant for our purpose of studying the gains from outsourcing relations in the South.

${ }^{10}$ This is equivalent to replacing the number of firms in (26) with its equilibrium value from (30) and then multiplying the two equations.
} 
Proposition 2 Given $\zeta^{* \prime}(\gamma)>0, \kappa^{\prime}\left(\zeta^{*}\right)<0$ and $\rho_{e}\left(\zeta^{*}\right)<0$, the impact of strengthening IPR enforcement on the host economy is twofold: reduced competition increases the average profits of the remaining more technologically capable firms in the intensive margin, while a reduction in the absolute number of firms on the extensive margin lowers total industry profits.

Proof. This follows directly from Lemma 2 and Proposition 1, Equations (31) and (32), and the definition of $\kappa\left(\zeta^{*}\right)$ in (27). That is, the derivative of $(32)$ with respect to $\zeta^{*}$ is:

$$
\frac{d(n \bar{\Pi})}{d \zeta^{*}}=\frac{E(1-\alpha)\left[\frac{\kappa^{\prime}\left(\zeta^{*}\right)}{\kappa\left(\zeta^{*}\right)^{2}}-\frac{\rho_{e}^{\prime}\left(\zeta^{*}\right)\left(w k_{f}+k_{s}\right)}{\delta f_{e}}\right]}{\left(\frac{1}{\kappa\left(\zeta^{*}\right)}+\frac{\rho_{e}\left(\zeta^{*}\right)\left(w k_{f}+k_{s}\right)}{\delta f_{e}}\right)^{2}} .
$$

The effect of an increase in $\zeta^{*}$ on aggregate industry profits depends on the sign of $\frac{\kappa^{\prime}\left(\zeta^{*}\right)}{\kappa\left(\zeta^{*}\right)^{2}}-\frac{\rho_{e}^{\prime}\left(\zeta^{*}\right)}{\delta} \lessgtr 0$. We know that $\kappa^{\prime}\left(\zeta^{*}\right)<0$ and $\rho_{e}^{\prime}\left(\zeta^{*}\right)<0$.

Next, we aim to show that IPR enforcement in technologically lagged economies represented by a fat right tail distribution of $G(\zeta)$ is more likely to have a negative effect on the upstream supplier market given the attributes of their relationships with downstream multinational firms. Gains from reduced competition in the intensive margin are not sufficient to compensate for losses on the extensive margin brought about by the exit of less capable suppliers. In such economies, less strict IPR enforcement generates a larger outside option for suppliers and creates gain by allowing more suppliers to operate in the economy and benefit from links to multinational firms. An interesting case is that of a Pareto distribution, in which the expression (33) turns to

$$
\frac{d(n \bar{\Pi})}{d \zeta^{*}}=\frac{E(1-\alpha) \frac{\beta\left(w k_{f}+k_{s}\right)}{\delta f_{e} \zeta^{* \beta+1}}}{\left(\beta+\frac{w k_{f}+k_{s}}{\zeta^{* \beta} \delta f_{e}}\right)^{2}}
$$

and is always positive but decreasing in the tail index $\beta$. In this case, gains from IPR protection are diminishing as countries are less developed as long as condition $\beta>1 / \ln \zeta^{*}$ holds. ${ }^{11}$ Similar to Melitz (2003), the downward sloping ZCP schedule turns flat under a Pareto distribution since $\kappa\left(\zeta^{*}\right)$ would no longer depend on $\zeta^{*}$. Consequently, the negative effect of IPRs in (33) goes down to zero, while it remains negative for other distributions where $\kappa^{\prime}\left(\zeta^{*}\right)<0$, more so the lower is the level of development in the host country (larger $\beta$ ). We can therefore make the general conclusion that

Proposition 3 Given the shape of the distribution function in $\kappa\left(\zeta^{*}\right)$ and $\rho_{e}\left(\zeta^{*}\right)$, an economy where the distribution of technology leans towards less technologically endowed suppliers is more likely to lose from (or less likely to gain from) IPR enforcement. This is due to a smaller positive effect of a change in $\zeta^{*}$ on aggregate profits in the intensive margin and a larger negative effect on the extensive margin.

\footnotetext{
${ }^{11}$ See the Appendix for proof.
} 
Proof. See the Appendix.

Finally, we turn to the welfare in the North, which consists of consumer utility and profits of the final producers. In standard IPR literature, consumers are worse off due to higher prices, but could also gain from more varieites or better qualities arising from innovation. On the other side of the market, Northern firms are generally considered to be the winners of stronger IPR enforcement in the South. Given the above analysis, it is straightforward to see that consumers in the North lose from IPR protection as a larger $\zeta^{*}$ reduces the number of firms and hence the number of varieties made available to Northern consumers through outsourcing. This is different from the standard channel of price changes and singles out the impact of IPRs on consumer welfare brought about by outsourcing. At the same time, a more strict IPR regime in the South increases the average profits of outsourcing for Northern multinationals, which helps explain the vigorous lobbying efforts by Northern firms for the implementation of the agreement on Trade-Related Aspects of Intellectual Property Rights (TRIPS) by the World Trade Organization (WTO).

Proposition 4 Consumers in the North lose from stronger IPR enforcement in the South due to a lower number of varieties, whereas average profits of outsourcing increase for Northern firms.

Proof. Given the utility function (1) and looking at (30), it is easy to see that $n$ and therefore (1) is decreasing in $\zeta^{*}$ since $\kappa^{\prime}\left(\zeta^{*}\right)<0$ and $\rho_{e}^{\prime}\left(\zeta^{*}\right)<0$. At the same time average profits $\bar{\Pi}$ in $(29)$ are increasing in IPRs since $\rho_{e}^{\prime}\left(\zeta^{*}\right)<0$.

\subsection{Robustness to Alternative Explanations}

The results obtained from this framework are robust to several parallel studies in the international trade and IPR literature and can be put into different contexts. To name a few we put our findings next to theory and evidence derived under the topic of imitation, technological complexity, and spillovers.

Starting with integration as an alternative to outsourcing in a foreign country, we mentioned in the literature review that Antràs and Helpman (2008) show how contract enforcement in the South increases the relative prevalence of FDI over outsourcing. Corcos et al. (2013) accordingly find evidence that imports from countries with well-functioning judicial institutions are more likely to be intra-firm. In other words, the better a country's judicial system, the less likely firms are to engage in outsourcing relationships. This can easily fit into our framework if the alternative to outsourcing is integration through FDI. An outsourcing relationship with the threshold supplier $\zeta^{*}$ would give $\Pi_{f}^{O U T}\left(\zeta^{*}\right)-w k_{f}^{O U T}=\Pi_{f}^{F D I}-w k_{f}^{F D I}$ as opposed to zero profits $\left(\Pi_{f}^{O U T}\left(\zeta^{*}\right)=w k_{f}^{O U T}\right)$. FDI profits do not rely on suppliers or depend on their capability as everything takes place within firm boundaries. Hence, in the present framework it can be treated as a fixed expression $\Pi_{f}^{F D I}=$ $\frac{E}{n}(1-\alpha)-\iota$, where we have used $\zeta=1$ as the firm does not exploit specialization gains from 
outsourcing and $\gamma=1$ due to no imitation risk and therefore no problem with the IPR regime under FDI. It is therefore always true that $\Pi_{f}^{O U T}(\zeta) \geq \Pi_{f}^{F D I}$, whereas the fixed costs of setting up an outsourcing relationship are higher than that for FDI $\left(k_{f}^{O U T}>k_{f}^{F D I}\right)$. Outsourcing would only take place with suppliers that possess a technology above the threshold $\zeta^{*}$ so that they can cover the extra fixed costs associated with outsourcing, i.e., $\Pi_{f}^{O U T}(\zeta)-w k_{f}^{O U T} \geq \Pi_{f}^{F D I}-w k_{f}^{F D I}$ for $\zeta \geq \zeta^{*}$. As IPR protection increases the threshold $\zeta^{*}$, outsourcing will be reduced and limited to the best suppliers, thereby giving way to FDI. More directly, this is also consistent with the general observations in IPR literature that a multinational will enter more aggressively when IPR enforcement is strengthened (Maskus and Penubarti, 1995; Smith, 2001; Branstetter et al., 2006; Ivus, 2010; Branstetter et al. 2011).

In the context of imitation, it was mentioned that in a weak IPR environment, suppliers are not obliged to respect the rules of the contract and can use their capability to defect and operate outside the relationship. This is parallel to imitation under a weak IPR regime, where licensing contracts are not respected and the licensees defect and use the acquired technology for their own purposes. Arora and Merges (2004) is among a number of papers under this branch of the literature that show how IPR protection may encourage investments in specialized firms with strong capabilities in the area of innovative input supply. IPRs can therefore play a role in determining the location of firm boundaries. This is consistent with evidence by Anand and Khanna (2000) in a study of 1,612 licensing agreements using data from the Strategic Alliance database of the Securities Data Company.

Moving to technological complexity, Acemoglu, Antràs and Helpman (2007) provide a theory to show that contract enforcement stimulates the adoption of more complex technologies through the firms' choice of suppliers. In a similar context, by using French firm-level data Naghavi, Spies, and Toubal (2015) provide evidence that firms outsource more complex technologies to countries that ensure stronger IPR protection. Our work can also be related to this context. Here, we show that stronger IPR enforcement shifts multinationals to form outsourcing relationships with suppliers endowed with better technologies by reducing the probability of defection.

Spillovers are another channel through which linkages between multinationals and local suppliers in a host country create benefits for both sides. Strong linkages with such firms have been associated with fostering production efficiency, productivity growth, and technological or managerial capabilities in supplier firms. Local suppliers therefore self-select into production for multinational firms. In particular Carluccio and Fally (2013) provide a theory that sheds light on how vertical spillovers from foreign firms can generate technology transfer and improve the productivity of upstream firms in the domestic industry. This is in line with evidence collected in an empirical survey by Alfaro and Rodriguez-Clare (2004) on manufacturing firms in Chile, Mexico, Venezuela and Brazil that are distinguished by sector and ownership. Our framework can be compared to this argument as 
strong IPR enforcement here also increases average technological capability in the supply chain. The channel is however different here as this is made possible by excluding the less capable suppliers from outsourcing relationships. In our framework, the previous findings are made possible through stronger IPR institutions.

\section{Conclusion}

This paper introduces supplier heterogeneity in the literature on firm organization in order to study the selection mechanism through which multinationals outsource to suppliers. Doing so allows us to study this decision under different IPR environments and highlights the impact of the latter on the host economy. In particular, we study suppliers that are heterogeneous in terms of their ability to make relationship-specific investments to customize the input according to standards required by the multinationals. Suppliers of high value-added and sophisticated products and services are in a better position to benefit from such partnerships than those with simpler processes.

In this setting multinationals provide suppliers with assistance in raising suppliers' technological capabilities and competitiveness to ensure that the inputs procured meet their stringent technical requirements. The extent of the technology transfer depends on the host economy and the level of development of local firms. Higher customization costs, less technologically endowed suppliers, and a weak IPR regime in the host country all increase the required amount of investment by the supplier. A multinational only offers such support when the investment can be expected to yield a reasonable return. They are more likely to source to domestic suppliers when the technological and managerial gaps between them and their local suppliers are not too wide to minimize training and technology transfer costs. In other words, when potential suppliers lack the minimum base of skills and know-how needed to absorb technologies and management practices, it becomes too costly for multinationals to transfer technology and train suppliers to match the required international standards. In countries with less adequate enforcement of IPRs, a higher outside option granted to less capable suppliers enables them to also operate in the customization of inputs and supplying parts to multinationals. Better IPR enforcement diverts attention along with the opportunity to obtain the necessary technical assistance and know-how towards a limited number of first-tier suppliers with relatively better technologies. This is because a better IPR environment obliges firms to invest more within the contractual relationship, only allowing more technologically advanced suppliers to survive by taking away the outside option of the less capable ones.

The subsequent elimination of less capable suppliers and an enhancement of the average $R \& D$ capability of the supply market also has numerous impacts on the host country. We find that better IPR enforcement has an ambiguous effect on the economy. Reduced competition increases the average profits in the industry in the intensive margin, whereas exit by less capable firms reduces 
aggregate profits on the extensive margin. Strict IPR enforcement can harm economies not endowed with a favorable distribution of technological capabilities. When a substantial mass of suppliers in the economy are on the low technology side, better IPR enforcement reduces intensive margin gains from lower competition, while increasing the extensive margin losses from a lower number of firms. Our results shed light on why IPR enforcement is given more importance in technologically advanced economies and continues to be neglected in countries such as China, which regardless enjoys an ever increasing share of outsourcing relationships worldwide.

A limitation of the model which we plan to tackle in the future is the fact that the partial equilibrium nature of the framework does not allow us to establish a comprehensive welfare analysis by measuring consumer surplus in the North. This is because although here consumers in the North may lose from IPRs in the South due to reduced outsourcing and hence a lower number of varieties, less outsourcing may not necessarily mean a reduced number of varieties as the goods could alternatively be provided locally or, as presented in Section 4.5, through other organizational forms such as FDI. We also hope this study can motivate the challenging task of collecting firm-level data that contains information regarding suppliers, in order to make possible a more in-depth analysis of outsourcing relationships between multinationals and subcontractors of different characteristics and attributes. 


\section{Appendix}

\section{Derivation of Equation (14)}

By substituting (11) into (12), the surplus for the supplier (net of costs already sunk) is

$$
\Pi_{s}=\omega \frac{E}{n}(1-\alpha)-\gamma \iota / \zeta+T
$$

and the surplus for the producer is found by substituting (10) into (13) to obtain

$$
\Pi_{f}=[1-\omega] \frac{E}{n}(1-\alpha)-T
$$

To derive the payment, the Nash product is maximized with respect to $T$

$$
\underset{T}{\operatorname{Max} \Pi}=\left[[1-\omega] \frac{E}{n}(1-\alpha)-T\right]^{1-\omega}\left[\omega \frac{E}{n}(1-\alpha)-\gamma \iota / \zeta+T\right]^{\omega} .
$$

By log-linearizing $\Pi$ we can rewrite

$$
\underset{T}{M a x} \ln \Pi=[1-\omega] \ln \left[[1-\omega] \frac{E}{n}(1-\alpha)-T\right]+\omega \ln \left[\omega \frac{E}{n}(1-\alpha)-\gamma \iota / \zeta+T\right]
$$

Solving for the FOC

$$
\frac{\partial \ln \Pi}{\partial T}=-\frac{1-\omega}{[1-\omega] \frac{E}{n}(1-\alpha)-T}+\frac{\omega}{\omega \frac{E}{n}(1-\alpha)-\gamma \iota / \zeta+T}=0
$$

yields

$$
T(\zeta, \gamma)=[1-\omega] \gamma \iota / \zeta
$$

Note that the expression $\gamma \iota / \zeta$ incorporates both the investment cost and the outside option. One can think of the outside option as $O=\zeta^{1-\beta} / \gamma$, i.e. increasing in productivity, $\zeta$, and decreasing

in IPR protection, $\gamma$, and the investment cost as $I=\iota / \zeta^{\beta}$, where $\beta$ determines the relevance of productivity within vis à vis outside the relationship. This yields $I / O=\gamma \iota / \zeta$ so that the supplier has a lower cost with higher productivity, (ii) a higher outside option with higher productivity, and (iii) a lower outside option with stronger IPR enforcement.

\section{Derivation of Equation (26)}

Solving

$$
\tilde{T}-\gamma \iota / \tilde{\zeta}=-\hat{\omega}_{f}\left(\frac{\zeta^{*}}{\tilde{\zeta}\left(\zeta^{*}\right)}\right)\left[\frac{E}{n}(1-\alpha)-w k_{f}-k_{s}\right]
$$


average net profits can be written in terms of $\zeta^{*}$ :

$$
\begin{aligned}
\bar{\Pi}_{s}= & \pi_{s}+\tilde{T}-\gamma \iota / \tilde{\zeta}-k_{s}=\hat{\omega}_{f}\left\{\frac{E}{n}(1-\alpha)-\left(\frac{\zeta^{*}}{\tilde{\zeta}\left(\zeta^{*}\right)}\right)\left[\frac{E}{n}(1-\alpha)-w k_{f}-k_{s}\right]\right\}-k_{s} \\
= & \left(1-\frac{w k_{f}}{\frac{E}{n}(1-\alpha)-\gamma \iota / \tilde{\zeta}}\right)\left\{\frac{E}{n}(1-\alpha)-\left(\frac{\zeta^{*}}{\tilde{\zeta}\left(\zeta^{*}\right)}\right)\left[\frac{E}{n}(1-\alpha)-w k_{f}-k_{s}\right]\right\}-k_{s} \\
= & \left(1-\frac{w k_{f}}{\frac{E}{n}(1-\alpha)-\left(\frac{\zeta^{*}}{\tilde{\zeta}\left(\zeta^{*}\right)}\right)\left[\frac{E}{n}(1-\alpha)-w k_{f}-k_{s}\right]}\right) \\
& *\left\{\frac{E}{n}(1-\alpha)-\left(\frac{\zeta^{*}}{\tilde{\zeta}\left(\zeta^{*}\right)}\right)\left[\frac{E}{n}(1-\alpha)-w k_{f}-k_{s}\right]\right\}-k_{s} \\
= & \frac{E}{n}(1-\alpha)-\left(\frac{\zeta^{*}}{\tilde{\zeta}\left(\zeta^{*}\right)}\right)\left[\frac{E}{n}(1-\alpha)-w k_{f}-k_{s}\right]-w k_{f}-k s \\
= & \left(1-\frac{\zeta^{*}}{\tilde{\zeta}\left(\zeta^{*}\right)}\right)\left[\frac{E}{n}(1-\alpha)-w k_{f}-k_{s}\right]
\end{aligned}
$$

where we have substituted for $\hat{\omega}_{f}$ from (23).

\section{Derivation of the Average Technological Capability}

Let us define the weighted average supplier technological capability measure according to Melitz (2003):

$$
\tilde{\zeta}=\int_{1}^{\infty} \zeta \mu(\zeta) d \zeta
$$

where the conditional distribution of $g(\zeta)$ on $\left[\zeta^{*}, \infty\right]$ is

$$
\mu\left(\zeta^{*}\right)=\int_{\zeta^{*}}^{\infty} \mu(\zeta) d \zeta=\frac{g(\zeta)}{1-G\left(\zeta^{*}\right)}
$$

from which we can rewrite average technological capability as

$$
\tilde{\zeta}\left(\zeta^{*}\right)=\frac{1}{1-G\left(\zeta^{*}\right)} \int_{\zeta^{*}}^{\infty} \zeta g(\zeta) d \zeta
$$

where $\tilde{\zeta}$ is uniquely derived by $\zeta^{*}$ and the exogenous distribution $g(\zeta)$ and $G(\zeta)$.

\section{Proof of Proposition 3}

It follows directly from Equation (32) and properties of the technology distribution function in (28) and (27). Looking back at the derivative of (32) with respect to $\zeta^{*}$ in (33), and recalling $\kappa^{\prime}\left(\zeta^{*}\right)<0$ and $\rho_{e}^{\prime}\left(\zeta^{*}\right)<0$, the technology distribution in the economy determines the size of each derivative. A poor distribution of technology, i.e. a fat right tail cumulative distribution of suppliers, implies a larger $\kappa^{\prime}\left(\zeta^{*}\right)$ and a smaller $\rho_{e}^{\prime}\left(\zeta^{*}\right)$, making it more likely for the expression to be negative. To see this consider the case of a Pareto distribution. We can define the probability density and the cumulative distributive function, $g(\zeta)$ and $G(\zeta)$, as

$$
g(\zeta)=\beta \zeta^{-\beta-1}
$$


and

$$
G(\zeta)=1-\zeta^{-\beta}
$$

where a larger $\beta$ implies a less technologically advanced economy in terms of the distribution of supplier capability, $\beta>1$ and $\frac{\beta}{\beta-1}$ is the mean. This in turn gives

$$
\int_{\zeta^{*}}^{\infty} \zeta g(\zeta) d \zeta=\int_{\zeta^{*}}^{\infty} \beta \zeta^{-\beta} d \zeta=\beta\left|\frac{1}{1-\beta} \zeta^{1-\beta}\right|_{\zeta^{*}}^{\infty}=\frac{\beta}{1-\beta}\left[\infty^{1-\beta}-\zeta^{* 1-\beta}\right]=\frac{\beta}{\beta-1} \zeta^{* 1-\beta} .
$$

Conditional average capability can be written as

$$
\frac{1}{1-G\left(\zeta^{*}\right)} \int_{\zeta^{*}}^{\infty} \zeta g(\zeta) d \zeta=\frac{\beta}{\beta-1} \frac{\zeta^{* 1-\beta}}{\zeta^{-\beta}}=\frac{\beta}{\beta-1} \zeta^{*}
$$

and used to derive

$$
\kappa\left(\zeta^{*}\right)=1-\frac{\zeta^{*}}{\tilde{\zeta}\left(\zeta^{*}\right)}=1-\frac{\zeta^{*}}{\frac{\beta}{\beta-1} \zeta^{*}}=1-\frac{\beta-1}{\beta}=\frac{1}{\beta}
$$

and

$$
\rho_{e}\left(\zeta^{*}\right)=1-G\left(\zeta^{*}\right)=\zeta^{*-\beta}
$$

The derivative of $\rho_{e}\left(\zeta^{*}\right)$ with respect to $\zeta^{*}$ is in turn

$$
\rho_{e}^{\prime}\left(\zeta^{*}\right)=-\beta \zeta^{*-\beta-1}
$$

If $G(\zeta)$ has a fat enough right tail, many firms are on the less capable side so that with a change in $\zeta^{*}, 1-G\left(\zeta^{*}\right)$ does not change much and does not have much effect on average profits (due to a smaller $\left.\rho_{e}^{\prime}\left(\zeta^{*}\right)\right)$. Formally, the expression $\rho_{e}^{\prime}\left(\zeta^{*}\right)=-\frac{\beta}{\zeta^{* \beta+1}}$ is decreasing in $\beta$ (for less developed economies) as long as $\beta>1 / \ln \zeta^{*}$.

Applying Pareto distribution to our argument gives

$$
n \bar{\Pi}=\frac{E(1-\alpha)}{\frac{1}{\kappa\left(\zeta^{*}\right)}+\frac{\rho_{e}\left(\zeta^{*}\right)\left(w k_{f}+k_{s}\right)}{\delta f_{e}}}=\frac{E(1-\alpha)}{\beta+\frac{w k_{f}+k_{s}}{\zeta^{* \beta} \delta f_{e}}}
$$

where

$$
\frac{d(n \bar{\Pi})}{d \zeta^{*}}=-\frac{E(1-\alpha) \frac{\rho_{e}^{\prime}\left(\zeta^{*}\right)\left(w k_{f}+k_{s}\right)}{\delta f_{e}}}{\left(\frac{1}{\kappa\left(\zeta^{*}\right)}+\frac{\rho_{e}\left(\zeta^{*}\right)\left(w k_{f}+k_{s}\right)}{\delta f_{e}}\right)^{2}}=\frac{E(1-\alpha) \frac{\beta\left(w k_{f}+k_{s}\right)}{\delta f_{e} \zeta^{* \beta+1}}}{\left(\beta+\frac{w k_{f}+k_{s}}{\zeta^{* \beta} \delta f_{e}}\right)^{2}}
$$

is always positive but decreasing in $\beta$ so that gains from IPR protection are diminishing as countries are less developed, as long as the condition above $\beta>1 / \ln \zeta^{*}$ holds. At the same time, while $\kappa^{\prime}\left(\zeta^{*}\right)=0$ under Pareto, it is negative for most distributions, and more so the less developed a country is, i.e. $\kappa^{\prime}\left(\zeta^{*}\right)$ is decreasing at a faster rate the fatter is the right tail and hence the larger is the negative effect of the presence of more competitive rivals on average profits. 


\section{References}

Acemoglu, D., Antràs, P. and Helpman, E. (2007) Contracts and Technology Adoption, American Economic Review 97, 916-943.

Ahmadijan, C. and Oxley, J. (2013) Vertical Relationships, Hostages, and Supplier Performance: Evidence from the Japanese Automotive Industry, Journal of Law, Economics and Organization, $29,485-511$.

Ahmadijan, C. and Oxley, J. (2006) Using Hostages to Support Exchange: Dependence Balancing and Partial Equity Stakes in Japanese Automotive Supply Relationships, Journal of Law, Economics and Organization, 22, 213-233.

Alfaro, L. and Rodriguez-Clare, A. (2004) Multinationals and Linkages: An Empirical Investigation, Economia 4(2).

Anand, B.N. and Khanna, T. (2000) The Structure of Licensing Contracts, Journal of Industrial Economics 48, 103-135.

Andrabi, T., Ghatak, M. and Khwaja, A.I. (2006) Subcontractors for Tractors: Theory and Evidence on Flexible Specialization, Supplier Selection and Contracting, Journal of Development Economics $79,273-302$.

Antràs, P. (2014) Grossman-Hart (1986) Goes Global: Incomplete Contracts, Property Rights, and the International Organization of Production, Journal of Law, Economics and Organization, 30 S1, i118-i174.

Antràs, P. and Helpman, E. (2008) Contractual Frictions and Global Sourcing, in Helpman, E., D. Marin, and T. Verdier, eds., The Organization of Firms in a Global Economy, Cambridge, MA: Harvard University Press.

Antràs, P. and Rossi-Hansberg E. (2009) Organizations and Trade, Annual Review of Economics $1(1), 43-64$.

Arora, A. and Merges, R.P. (2004) Specialized Supply Firms, Property Rights and Firm Boundaries, Industrial and Corporate Change 13, 451-475.

Assche, A.V. and Schwartz, G.A. (2010) Input Specificity and Global Sourcing, Journal of the Japanese and International Economies 24, 69-85.

Branstetter, L., Fisman, R. and Foley, F. (2006). Does Stronger Intellectual Property Rights Increase International Technology Transfer? Empirical Evidence from U.S. Firm-level Data. Quarterly Journal of Economics 121(1), 321-349.

Branstetter, L., R. Fisman, F. Foley, and Saggi, K. (2011). Does Intellectual Property Rights Reform Spur Industrial Development? Journal of International Economics 83, 27-36.

Canals, C. and Şener, F. (2014) Offshoring and Intellectual Property Rights Reform, Journal of Development Economics 108, 17-31.

Carluccio, J. and Fally, T. (2013) Foreign Entry and Spillovers with Technological Incompatibilities 
in the Supply Chain, Journal of International Economics 90, 123-135.

Che, J., Qiu, L.D. and Zhou, W. (2014) Entry, Reputation and Intellectual Property Rights Enforcement, Canadian Journal of Economics 47 (4).

Chu, A.C, Cozzi, G. and Galli, S. (2014) Stage-dependent Intellectual Property Rights, Journal of Development Economics 106, 239-249.

Corcos, G., Irac, D.M., Mion, G. and Verdier, T. (2013) The Determinants of Intra-Firm Trade, The Review of Economics and Statistics, 95(3), 825-838.

Costinot, A. (2009) On the Origins of Comparative Advantage, Journal of International Economics 77, 255-264.

Defever, F. and Toubal, F. (2013) Productivity, Relation-Specific Inputs and the Sourcing Modes of Multinationals, Journal of Economic Behavior and Organization 94, 245-357.

Grossman, G. M. and Helpman, E. (2002) Integration vs. Outsourcing in Industry Equilibrium, Quarterly Journal of Economics 117, 85-120.

Grossman, G.M. and Helpman, E. (2003) Outsourcing versus FDI in Industry Equilibrium, Journal of the European Economic Association 1, 317-327.

Grossman, G.M. and Helpman, E. (2005) Outsourcing in a Global Economy, Review of Economic Studies 72, 135-159.

Helpman, E. (2006) Trade, FDI, and the Organization of Firms, Journal of Economic Literature 44, $589-630$.

Ivus, O. (2010) Do Stronger Patent Rights Raise High-tech Exports to the Developing World? Journal of International Economics 81 (1), 38-47.

Kamath, R. and Liker J. (1994) A Second Look at Japanese Product Development. Harvard Business Review 72, 154-170.

Lai, E.L.-C and Qiu, L.D. (2003) The North's Intellectual Property Rights Standard for the South? Journal of International Economics 59 (1), 183-209.

Levchenko, A. (2007) Institutional Quality and International Trade, Review of Economic Studies 74, 791-819.

Lin, P. and Saggi, K. (2007) Multinational Firms, Exclusivity, and Backward Linkages, Journal of International Economics 71, 206-220.

Maskus, K.E. and Penubarti, M. (1995) How Trade Related are Intellectual Property Rights? Journal of International Economics 39, 227-248.

McLaren, J. (2000) Globalization and Vertical Structure, American Economic Review 90, 1239-1254. Melitz, M. J. (2003) The Impact of Trade on Intra-Industry Reallocations and Aggregate Industry Productivity, Econometrica 72, 1695-1725.

Naghavi, A., Spies, J., and Toubal, F. (2015) Intellectual Property Rights, Product Complexity, and the Organization of Multinational Firms, Canadian Journal of Economics 48 (3), 881-902. 
Nunn, N. (2007) Relationship-Specificity, Incomplete Contracts, and the Pattern of Trade, Quarterly Journal of Economics 122, 569-600.

Qiu, L.D. and Spencer, B. J. (2001) Keiretsu and Relationship-Specific Investment: A Barrier to Trade? International Economic Review 42, 871-901.

Qiu, L.D. and Spencer, B. J. (2002) Keiretsu and Relationship-Specific Investment: Implications for Market-Opening Trade Policy, Journal of International Economics 58, 49-79.

Smith, P. (2001) How do Foreign Patent Rights Affect U.S. Exports, Affiliate Sales, and Licenses? Journal of International Economics 55 411-439.

Sutton, J. (2004) The Auto-component Supply Chain in China and India A Benchmarking Study", mimeo, London School of Economics.

UNCTAD (2001), World Investment Report 2001: Promoting Linkages. United Nations, New York and Geneva. 